\title{
Differential Colonization of Tomato Roots by Nonpathogenic and Pathogenic Fusarium oxysporum Strains May Influence Fusarium Wilt Control
}

\author{
Jian R. Bao and George Lazarovits
}

First author: Department of Plant Science, University of Western Ontario, London, Canada; and first and second authors: Southern Crop Protection and Food Research Center, Agriculture and Agri-Food Canada, 1391 Sandford St., London, ON, N5V 4 T3.

Current address of J. R. Bao: U.S. Department of Agriculture-Agricultural Research Services, Vegetable Development Laboratory, Beltsville, MD 20705.

Accepted for publication 19 January 2001.

\begin{abstract}
Bao, J. R., and Lazarovits, G. 2001. Differential colonization of tomato roots by nonpathogenic and pathogenic Fusarium oxysporum may influence Fusarium wilt control. Phytopathology 91:449-456.

Histochemical staining, $\beta$-glucuronidase (GUS) activity, or placing roots on agar were methods used to characterize interactions between the pathogenic fungus, Fusarium oxysporum f. sp. lycopersici, and the nonpathogenic biocontrol $F$. oxysporum strain $70 \mathrm{~T} 01$ with respect to colonization behaviors, interaction sites, and population densities on tomato roots. Mycelia of strain 70T01, a genetic transformant expressing stable GUS activity, hygromycin B resistance, and effective disease control, were localized in epidermal and cortex cell layers of tomato roots in a discontinuous and uneven pattern. In contrast, mycelia of $F$. oxysporum f. sp. lycopersici were found in the vascular bundles. Thus,

the inoculation density but decreased with distance from the inoculation site. Host defense reactions, including increased cell wall thickness or papilla deposits, were adjacent to 70T01 hyphae. Experiments done in soil showed that strain $70 \mathrm{~T} 01$ densities in roots were highest at inoculation zones and barely detectable for root segments more than $2 \mathrm{~cm}$ away from the inoculation sites. F. oxysporum f. sp. lycopersici densities were lowest at 70T01 inoculation zones and highest ( $>10$ times) where strain 70T01 was not directly applied. Newly elongating roots where strain 70T01 did not reach were available for infection by the pathogen. The higher strain 70T01 density was always found when the plants were simultaneously infected by $F$. oxysporum f. sp. lycopersici, suggesting that $F$. oxysporum $\mathrm{f}$. sp. lycopersici has as much influence in predisposing the plant to colonization by strain 70T01 as strain 70T01 has on providing disease protection against the pathogen.
\end{abstract} direct interactions between the two fungi likely happen in the root surface cell layers. Colonization density of strain 70T01 was related to

Disease suppression by biocontrol agents is the sustained manifestation of interactions among the plant, pathogen, biocontrol agent, and environments (13). Despite the potential use of biocontrol agents in agricultural applications, biological control remains one of the most poorly understood areas of plant-microbe interactions (13). Excellent model systems for studies of such interactions have become available with the recent successes found in protecting diverse crop plants from Fusarium wilts using nonpathogenic (NP) Fusarium oxysporum (1,16,24). Although significant disease reductions were obtained in a controlled environment, many NP F. oxysporum strains were less effective as crop protectants under field conditions $(18,24)$. Although numerous mechanisms for disease control have been proposed $(3,16$, 24,28 ), we do not yet have sufficient information to fully exploit NP F. oxysporum strains for commercial use. This lack of information is mostly related to difficulties involved in studying interactions between the pathogenic Fusarium and the NP F. oxysporum strain in the rhizosphere and soil. We are not only unable to measure populations of the two organisms on roots, but are also incapable of differentiating them from each other, or from the numerous other morphologically identical $F$. oxysporum strains

Corresponding author: G. Lazarovits; E-mail address: lazarovitsg@em.agr.ca

Publication no. P-2001-0301-01R

This article is in the public domain and not copyrightable. It may be freely reprinted with customary crediting of the source. The American Phytopathological Society, 2001.
Additional keywords: root colonization. that are common residents on plants and in soil. In biological control, root colonization is presumed to be important for many antagonists, but the inability to accurately assess colonization has hampered research efforts. Thus, the location of the NP F. oxysporum strain either on or in a plant root, the extent of its presence in comparison to root biomass or to the pathogen, and the behaviors of both the NP F. oxysporum strain and the pathogenic when introduced together remain unclear.

Molecular markers now make it possible to specifically tag an organism, track its location in complex ecosystems, and observe the interactions. Markers such as $\beta$-glucuronidase (GUS) have been successfully used to tag fungi in studies on fungal-host or fungal-fungal interactions $(7,19,20,27)$, including interactions with biocontrol agents $(9,12,21,32)$. Colonization by a GUSmarked NP $F$. oxysporum strain on tomato roots was observed directly using a hydroponic cultivation system (21), but impacts on the NP F. oxysporum strain and its colonization that may have arisen from the presence of the pathogen or the complex microbial community in soil have not been documented. In this study, we used a genetically marked NP F. oxysporum strain (70T01) that was derived from a biological control capable NP $F$. oxysporum strain SA70 (3), to determine the root colonization activity on tomato seedlings grown on agar medium in the absence and presence of a pathogen ( $F$. oxysporum $\mathrm{f}$. sp. lycopersici, race 1$)$ and to delineate interactions under conditions ideal for making observations and for fungal colonization and disease development. Fungal mycelia in the roots were examined by histochemical staining that differentiated the two organisms. This was then expanded to characterize root colonization behavior of $70 \mathrm{~T} 01$ or F. oxysporum $\mathrm{f}$. 
sp. lycopersici in pasteurized soil through a tomato transplantation system. The design of these experiments was intended to take advantage of the transplant plugs as a delivery route for the biocontrol agent. The potential for control after transplantation of the plugs into conditions of infestation by a pathogen could then be determined.

\section{MATERIALS AND METHODS}

Fungal strains and culture condition. F. oxysporum strain $70 \mathrm{~T} 01$ (3), expressing both the hygromycin B (HmB) resistance gene $(h p h)(25)$ and the GUS gene (gusA) (14), was a genetically transformed line derived from NP $F$. oxysporum strain SA70, which has disease suppressing activity against the tomato Fusarium wilt pathogen ( $F$. oxysporum f. sp. lycopersici) (3). A strain of $F$. oxysporum f. sp. lycopersici race 1 (provided by R. Brammall, Barammall Phytotec, Wodstock, Ontario) was used as a pathogen for tomato plants in this study. Fungal cultures were routinely grown on potato dextrose agar (PDA) (Difco Laboratories, Detroit) medium at $25^{\circ} \mathrm{C}$. PDA amended with $50 \mu \mathrm{g}$ of $\mathrm{HmB}$ per ml (PDAH) or potato dextrose broth (PDB) with $10 \mathrm{ng}$ of $\mathrm{HmB}$ per $\mathrm{ml}(\mathrm{PDBH})$ was used for growth of the transformant. For the production of fungal spores, $50 \mathrm{ml}$ of $\mathrm{PDBH}$ inoculated with $10^{7}$ spores of the transformant $70 \mathrm{T01}$ was incubated for 5 days at $25^{\circ} \mathrm{C}$ on a rotary shaker $(150 \mathrm{rpm})$. Komada (K) agar medium (15) amended with $50 \mu \mathrm{g} / \mathrm{ml} \mathrm{HmB} \mathrm{(KH} \mathrm{me-}$ dium) was used to numerate the CFU of strain $70 \mathrm{~T} 01$ in tomato root tissues.

Aseptically grown tomato seedlings and inoculation with fungi. Tomato (Lycopersicon esculentum Mill., cv. Bonny Best; Ontario Seed Company Ltd., Waterloo), which is very susceptible to Fusarium wilt, was used as the host for the fungal strains. Tomato seedlings were produced either aseptically on nutrient agar medium or in plug cells containing potting mixture (Promix; Premier Horticulture Ltd., QU, Canada). Plug seedlings were used as transplants into soil. Aseptically grown tomato seedlings were derived from surface-disinfested seeds that were obtained by briefly washing in $0.1 \%$ detergent solution, followed by soaking for $10 \mathrm{~min}$ in $0.3 \%$ sodium hypochlorite (Javex, Toronto, ON, Canada), and rinsing in sterile distilled water. Seeds were then transferred onto petri plates containing $1.5 \%(\mathrm{wt} / \mathrm{vol})$ water agar for germination at $25^{\circ} \mathrm{C}$. When seedlings had roots approximately 2 to $3 \mathrm{~cm}$ long, roots were inoculated by immersion for $1 \mathrm{~min}$ in a spore suspension either with $70 \mathrm{~T} 01\left(10^{7}\right.$ spores per $\left.\mathrm{ml}\right), F$. oxysporum f. sp. lycopersici $\left(10^{6}\right.$ spores per $\left.\mathrm{ml}\right)$, or both $\left(10^{7}+\right.$ $10^{6}$ spores per $\mathrm{ml}$, respectively). Five inoculated seedlings were placed into a Magenta box $(6 \times 6 \times 8 \mathrm{~cm}$; Sigma Chemical, St. Louis) containing $25 \mathrm{ml}$ of sterilized modified Murashige and Skoog medium $\left(1.5 \mathrm{~g}\right.$ of $\mathrm{KNO}_{3}, 0.4 \mathrm{~g}$ of $\mathrm{CaCl}_{2} \cdot 2 \mathrm{H}_{2} \mathrm{O}, 0.3 \mathrm{~g}$ of $\mathrm{MgSO}_{4} \cdot 7 \mathrm{H}_{2} \mathrm{O}, 0.15 \mathrm{~g}$ of $\mathrm{KH}_{2} \mathrm{PO}_{4}, 0.1 \mathrm{~g}$ of $\mathrm{FeSO}_{4} \cdot 7 \mathrm{H}_{2} \mathrm{O}$, and $7.0 \mathrm{~g}$ of Noble agar per 1 liter of water) with no added carbon source (22). Plants in Magenta boxes were placed into a growth chamber with $14 \mathrm{~h}$ of light at $25^{\circ} \mathrm{C}$ and $10 \mathrm{~h}$ of darkness at $20^{\circ} \mathrm{C}$. After 10 days, plant roots were excised from below the crown and used for the following experiments.

Histochemical staining and root sections for light microscopic observation. Mycelia of strain $70 \mathrm{~T} 01$ and $F$. oxysporum $\mathrm{f}$. sp. lycopersici inside tomato roots were differentiated histochemically using the reaction products formed when the GUS enzyme reacts with the substrate 5-bromo-4-chloro-3-indoyl- $\beta$-D-glucuronide (X-Gluc) (B-6650; Sigma Chemical, St. Louis). Root samples from aseptically inoculated seedlings were stained using a modification of the procedure described by Stomp (30). Whole roots or $1.5 \mathrm{~cm}$ long segments, cut from just below the crown, were washed three times with $50 \mathrm{mM}$ phosphate buffer $(\mathrm{pH} 7.0)$, prefixed for $10 \mathrm{~min}$ under a vacuum in $0.1 \%$ glutaraldehyde (GA, in phosphate buffer), rinsed five times with the same buffer, and placed in X-Gluc-staining solution $(50 \mathrm{mM}$ phosphate buffer at
$\mathrm{pH} 7.0,0.5 \mathrm{mM}$ potassium ferricyanide, $0.5 \mathrm{mM}$ potassium ferrocyanide, $10 \mathrm{mM}$ EDTA, $0.1 \%$ Triton X-100, and $1.0 \mathrm{mM}$ X-Gluc) at $37^{\circ} \mathrm{C}$ overnight. Stained roots were washed five times with phosphate buffer, fixed in $3 \% \mathrm{GA}$ for $1 \mathrm{~h}$, then in 5\% formaldehyde, $5 \%$ acetic acid, and $20 \%$ ethanol (vol/vol/vol) fixation solution for $5 \mathrm{~min}$, washed again, and stored in phosphate buffer at $4^{\circ} \mathrm{C}$ before further processing.

X-Gluc-stained root segments were dehydrated with an automatic Neuro-Processor (Histomatic-226MP; Fisher Scientific, Pittsburgh) programmed to provide $1 \mathrm{~h}$ changes in the following solutions: 70,80 , and $95 \%$ ethanol, three consecutive changes in $100 \%$ ethanol, and three consecutive soaks in xylene, all at room temperature. The roots were then placed in molten paraffin at 56 to $58^{\circ} \mathrm{C}$ for $3 \mathrm{~h}$, followed by three transfers in fresh paraffin, then embedded in paraffin, and sectioned into 5 to $10 \mu \mathrm{m}$ thick sections with a microtome (Reicheit Jung 2040, Oberkochen, Germany). The sections were mounted on glass microslides (Superfrost Plus; Fisher Scientific, Fair Lawn, NJ), dried in an incubator at $37^{\circ} \mathrm{C}$ overnight, dehydrated in $30,50,70$, and $100 \%$ ethanol gradients with 2 min for each step, and dewaxed in pure xylene twice for $5 \mathrm{~min}$ each. Sections were either directly mounted for observation with a cover slide using a few drops of Permount (Fisher Scientific, Ottawa, Canada) or they were further stained with Pianeze staining solution according to the procedures cited from Dhingra and Sinclair (8). Mycelia of strain 70T01 were stained blue with X-Gluc staining solution (30), whereas nontransformant fungal mycelia were stained deep pink by Pianeze staining solution (8). Sections were examined under a microscope (Leitz, Wetzlar, Germany) and photographed with Kodak slide film (Ektachrome 160 Tungsten; Kodak, Rochester, NY).

GUS activity measurement. GUS activity measurements were based on procedures described previously $(3,11)$. The enzyme was extracted from $50 \mathrm{mg}$ of tissue from 70T01-inoculated roots by homogenization in $1 \mathrm{ml}$ of ice-cold GUS buffer $(50 \mathrm{mM} \mathrm{NaHPO}$ at $\mathrm{pH}$ 7.0, $10 \mathrm{mM} \beta$-mercaptoethanol, $10 \mathrm{mM} \mathrm{Na} 2$ EDTA, $0.1 \%$ sodium lauryl sarcosine, and $0.1 \%$ Triton $\mathrm{X}-100$ ) according to the FastPrep method (Model FP120; Bio/Can Scientific Inc., Mississauga, ON, Canada) at speed setting four for $40 \mathrm{~s}$. Homogenates were centrifuged in a microcentrifuge at $10,000 \times g$ for $30 \mathrm{~min}$ at $4^{\circ} \mathrm{C}$ and the supernatants were used for GUS activity assays. GUS enzyme activity was determined with a fluorometer (Fluorolite 1000; Dynex, Chantilly, VA) following reaction with the substrate 4-methylumbelliferyl- $\beta$-D-glucuronide (M-5664, Sigma Chemical) (3). GUS activity was calculated based on the amount of the enzyme reaction product 4-methylumbelliferyl produced (nanomole or picomole) per minute or per unit of root weight.

CFU determination. Fungal CFU in roots were determined by placing serial dilutions of root homogenate on $\mathrm{K}$ or $\mathrm{KH}$ medium and counting the colonies formed. Roots (50 mg fresh weight) were homogenized on a FastPrep homogenizer at speed setting four for $40 \mathrm{~s}$ by loading into a 2 -ml plastic homogenization tube containing two ceramic beads and $1 \mathrm{ml}$ of ice-cold GUS buffer as described by Bao et al. (3). The total number of CFU of Fusarium was counted from $\mathrm{K}$ medium, 70T01 CFU from $\mathrm{KH}$ medium, and F. oxysporum f. sp. lycopersici $\mathrm{CFU}$ were estimated by subtracting 70T01 CFU from the total CFU.

GUS activity in root segments selected from various distances from the inoculated sites of aseptically grown plants. Tomato plants were prepared aseptically in Magenta boxes and were inoculated with spores of strain 70T01 as described previously. Roots were sampled from 10-day-old tomato plants by excising the root from the crown site, washing in phosphate buf fer ( $\mathrm{pH}$ 7.0) five times, and drying briefly on clean paper towels. Three types of root segments were excised: (i) inoculation site from the crown site to approximately $2 \mathrm{~cm}$ below; (ii) the segments from 2 (noninoculation segments) to $3 \mathrm{~cm}$; or (iii) from 3 to $4 \mathrm{~cm}$ down from the crown site. Root segments were weighed and 
homogenized, and GUS activity was determined. The experiment was carried out twice, and each replicate comprised five plant roots.

Effect of varying strain 70T01 and $F$. oxysporum f. sp. lycopersici inoculum ratios on GUS activity and $F$. oxysporum f. sp. lycopersici population size. Roots of aseptically grown tomato seedlings were inoculated with the two fungal spore suspensions at different $F$. oxysporum f. sp. lycopersici/70T01 spore density ratios: $10^{7}: 0,0: 10^{7}, 10^{7}: 10^{6}, 10^{7}: 10^{7}$, or $10^{6}: 10^{7}$ per milliliter. Inoculated plants were grown for 10 days in Magenta boxes in a growth chamber. Roots were destructively sampled, and GUS activity and $F$. oxysporum f. sp. lycopersici CFU were determined. The experiment was repeated once with three replicates for each treatment.

Determination of strain 70T01 and $F$. oxysporum f. sp. $l y$ copersici population densities in transplant roots in pasteurized soil. Plug plants were generated by placing a single seed in each plastic cell $(2.5 \times 2.5 \times 4.5 \mathrm{~cm})$ containing approximately $1 \mathrm{~g}$ of dry Promix that had been amended with spore suspension to $5 \times 10^{6}$ spores of 70T01 per gram or an equivalent amount of water for the control. Trays holding the cells were placed in the growth chamber as previously described and watered daily for 2 weeks before seedlings were transplanted into soil pots. The soil used for the transplants was a mixture of a sandy loam soil,
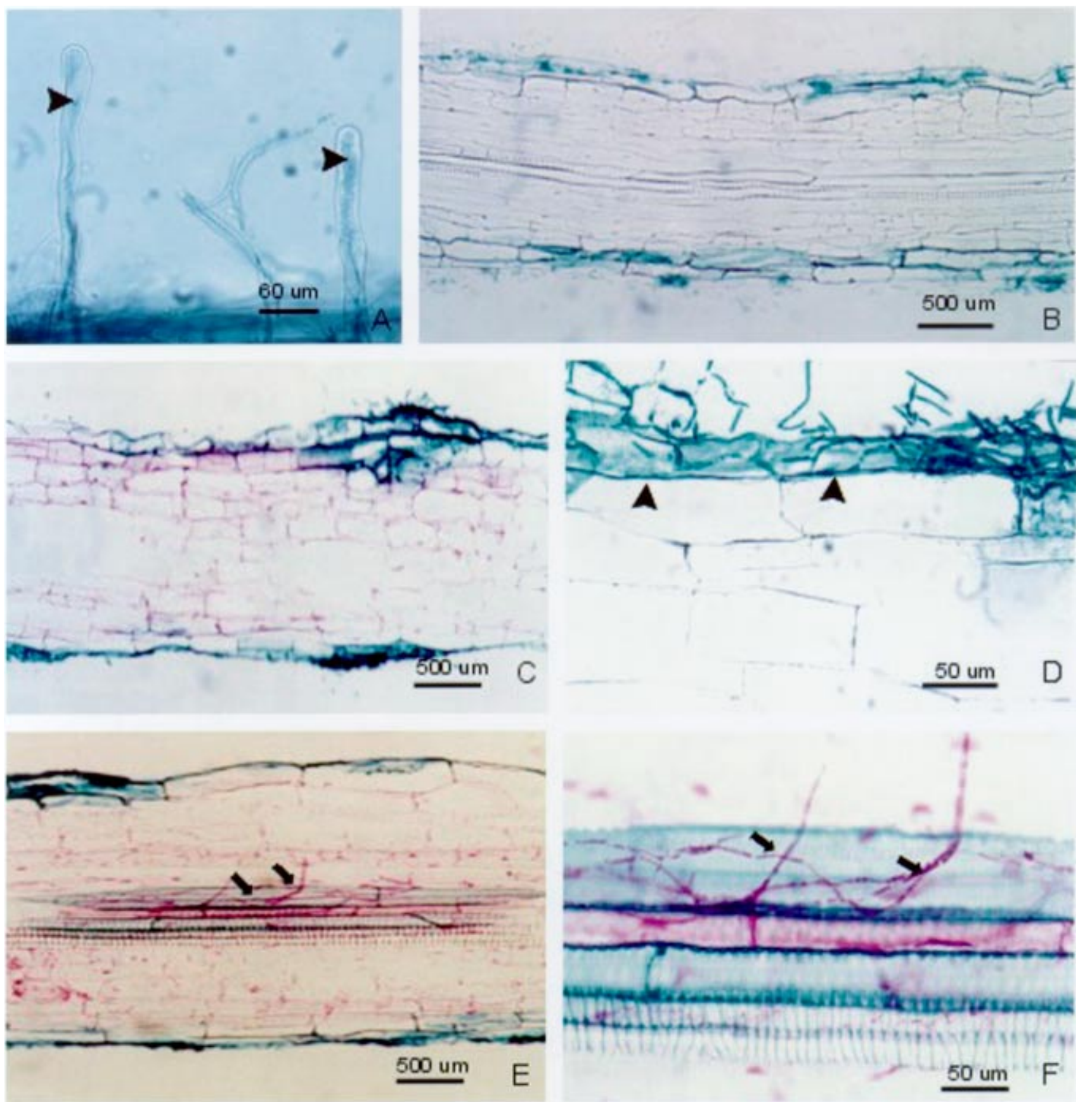

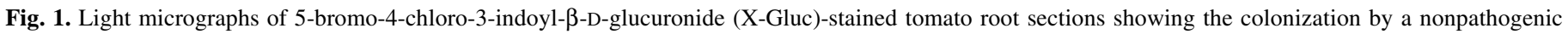

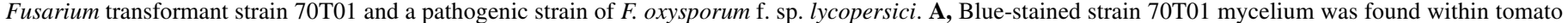

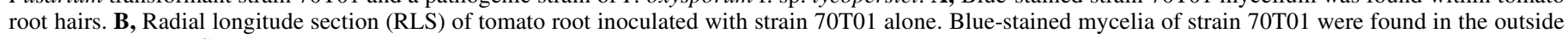

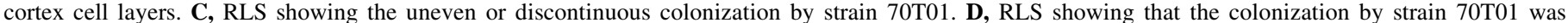

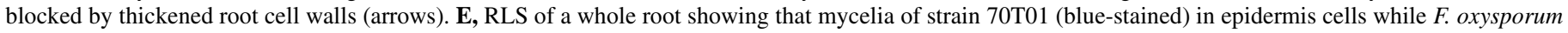

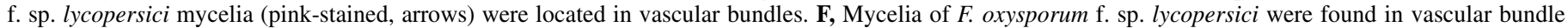
(pink-stained, arrows). 
obtained from a potato plot at the University of Guelph Research Farm at Simcoe, Ontario, and beach sand at 1:1 (wt/wt) and pasteurized in an oven at $70^{\circ} \mathrm{C}$ overnight to minimize the interference from soil microorganisms. F. oxysporum f. sp. lycopersici-inoculated soil was prepared by mixing the soil with sufficient powdered $F$. oxysporum $\mathrm{f}$. sp. lycopersici culture on wheat bran to give an inoculum concentration of $10^{5} \mathrm{CFU} / \mathrm{g}$ of dry soil. Two-week-old seedlings, along with the adhering Promix plug, were transplanted into either non- $F$. oxysporum f. sp. lycopersici-inoculated or $F$. oxysporum f. sp. lycopersici-inoculated soil. The roots were buried to just below the soil line in the center of 12.5 -cm-diameter plastic pots. Seedlings were incubated in growth cabinets as previously described. Disease development of the plants was observed periodically based on a disease severity scale ranging from 0 to 4 (Table 1). Plants were not watered for $24 \mathrm{~h}$ prior to sampling in order to separate the roots from soil more easily. At the sampling time, pot was inverted and gently shaken to remove loose soil revealing the plug, and the whole plant plug was carefully separated from the pot soil. The roots outside the plug (in the soil region) and inside the plug roots were excised. These roots were rinsed under gently running water to remove the visible nonroot attachments and dried of excess moisture on paper towels. Roots from each seedling and each zone below were cut into small sections, mixed, and 50-mg root segments were randomly sampled. Five plants per treatment were tested at each sampling interval for GUS activity assays and CFU determination. Two experiments were carried out using the identical procedures, except sampling times and root zones differed.

In the first experiment, root segments were taken from inside the Promix plugs (in-plug root zone, inoculation zone) and from soil external to the plug (exo-plug root zone, noninoculation zone) at $0,10,20$, or 30 days posttransplantation. In the second experiment, root segments were sampled from inside the Promix plugs (in-plug root zone) approximately $2 \mathrm{~cm}$ away from the plug edge (intermediate root zone) and approximately $3 \mathrm{~cm}$ away from the plug edge (distal root zone) at 1, 2, 3, or 4 weeks posttransplantation. Each plant was used for both GUS activity and CFU assays.

Statistical analysis. One-way analysis of variance was carried out using SigmaStat 1.0 statistical software (Jandel Scientific, San Rafael, CA). Significance was evaluated at $P<0.05$ for all tests, and multiple pairwise comparisons were obtained with the Student-Newman-Keuls test.

\section{RESULTS}

Localization of strain 70T01 and $F$. oxysporum f. sp. lycopersici in root sections under light microscopy. Mycelia of strain 70T01 were easily identifiable in and on tomato roots by their distinct blue color following treatment with X-Gluc. Many hyphal fragments were found inside root hairs with no apparent damage to these structures (Fig. 1A). Hyphae of strain 70T01 were pri- marily located in the intercellular spaces of the outer cortex cell layers (Fig. 1B and C). They colonized the length of the root in an uneven and discontinuous fashion (Fig. 1B to D). Attempted penetrations of root cells by hyphae were associated with increased cell wall thickness (Fig. 1D). Mycelia of strain 70T01 were rarely found in the inner cortex cell layers and never in vascular bundles (Fig. 1B and C). In contrast, F. oxysporum f. sp. lycopersici mycelia, which were recognizable by their deep pink color following Pianeze staining, were found in the vascular tissues (Fig. 1E and F). Mycelia of F. oxysporum f. sp. lycopersici were rarely observed in sections from roots that had been inoculated with both strain 70T01 and F. oxysporum f. sp. lycopersici, particularly in the regions where strain 70T01 had colonized.

In some instances, on plants inoculated with both strain 70T01 and $F$. oxysporum f. sp. lycopersici, mycelia of strain 70T01 were also found in the inner cortex cell layers of roots. These sections were invariably from roots of plants that had visible wilt symptoms caused by strain $F$. oxysporum $\mathrm{f}$. sp. lycopersici. In these sections, cell walls were partially disrupted, and unstained mycelia of strain F. oxysporum f. sp. lycopersici by X-Gluc were observed nearby.

GUS activity in root segments selected at various distances from the inoculated sites of aseptically grown plants. Three different root zones were analyzed for their GUS activity levels per milligram of root (Fig. 2), and the inoculated root zone had the highest GUS activity, approximately five times that of tissues $2 \mathrm{~cm}$ away from the inoculation zone. Root segments $3 \mathrm{~cm}$ away from the inoculated zone had the lowest GUS activity.

Effect of varying strain 70T01 and $F$. oxysporum f. sp. $l y$ copersici inoculum ratios on GUS activity and $F$. oxysporum $f$. sp. lycopersici population size. Aseptically grown tomato roots inoculated with $F$. oxysporum f. sp. lycopersici plus $70 \mathrm{T01}$ (spore density ratio at $10^{7}: 10^{6}$ ) had the highest GUS activity in all the treatments tested (Fig. 3). Roots treated with $F$. oxysporum f. sp. lycopersici plus 70T01 at inoculum density ratios of $0: 10^{7}$, $10^{7}: 10^{7}$, or $10^{6}: 10^{7}$ had lower GUS activity levels with no significant differences among them. Roots inoculated with either $F$. oxysporum f. sp. lycopersici alone (ratio $10^{7}: 0$ ) or water had no detectable GUS activity. Based on CFU, population sizes of strain 70T01 were not significantly different among all inoculated roots. CFU counts for strain $F$. oxysporum f. sp. lycopersici were highest in roots inoculated with $F$. oxysporum f. sp. lycopersici plus 70T01 at the $10^{7}: 10^{6}$ ratio but did not differ significantly from those inoculated with $F$. oxysporum f. sp. lycopersici alone. The roots inoculated with $10^{7}: 10^{7}$ or $10^{6}: 10^{7}$ ratios had significantly lower $F$. oxysporum f. sp. lycopersici population sizes than those inoculated with $F$. oxysporum f. sp. lycopersici alone or $10^{7}: 10^{6}$ inoculum ratio and actually reached an undetectable level.

Determination of 70T01 and $F$. oxysporum f. sp. lycopersici population densities in transplant roots in soil. Plants treated with the strain 70T01 had lower disease severity (Table 1) and had

TABLE 1. Severity of wilt of tomato seedlings with and without pre-inoculation with a nonpathogenic (NP) Fusarium oxysporum isolate $70 \mathrm{T01}$ after transplantation into soil containing the pathogen F. oxysporum f. sp. lycopersici ${ }^{\mathrm{V}}$

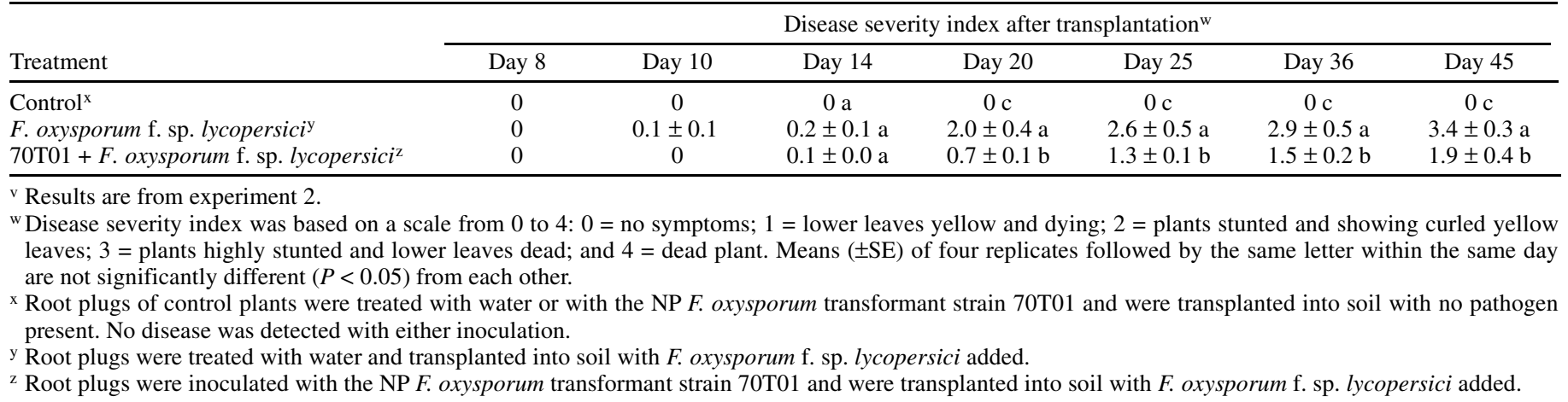


similar disease control results in both the experiments. Fungal population results from the two experiments had the same trends, and the results of the second experiment are presented in Figure 4. The highest levels of GUS activity were found in the in-plug roots inoculated with strain 70T01, whereas intermediate or distal roots had very little GUS activity. In-plug roots co-inoculated with 70T01-F. oxysporum f. sp. lycopersici had two to four times higher levels of GUS activity than those treated with strain 70T01 alone (Fig. 4A). Co-inoculation did not change the GUS activity in the intermediate or distal roots where the values were similar to those found with inoculation of strain 70T01 alone (Fig. 4B and C). Water- and F. oxysporum f. sp. lycopersici-treated plants had some GUS activity background in all three zones, but levels were much lower than those treated with strain 70T01.

Based on CFU per milligram of root, exo-plug roots inoculated with strain 70T01 alone had similar levels to those found in the first experiment where there was a linear decline over time in CFU (Fig. 4D). Again, the population density of strain 70T01 in both intermediate and distal roots was barely measurable (Fig. 4E and F). In this experiment however, strain 70T01 when co-inoculated with $F$. oxysporum f. sp. lycopersici had somewhat higher numbers than when inoculated alone (Fig. 4D). When strain $F$. oxysporum f. sp. lycopersici was inoculated alone, the number of CFU on in-plug roots was similar to that of strain 70T01 alone. Here co-inoculation with the two fungi significantly reduced $F$. oxysporum f. sp. lycopersici population sizes in the in-plug roots compared to those when strain $F$. oxysporum f. sp. lycopersici was added by itself (175 versus $25 \mathrm{CFU}$ ) over all sampling periods (Fig. 4D). Co-inoculation with strain 70T01 however, did not reduce $F$. oxysporum f. sp. lycopersici population densities in the intermediate or distal root zones, where population densities of $F$. oxysporum f. sp. lycopersici were somewhat higher than in roots inoculated with strain $F$. oxysporum f. sp. lycopersici alone, although the variability in measurements was quite large. $F$. oxysporum f. sp. lycopersici population sizes in intermediate roots ranged from 160 to $900 \mathrm{CFU}$ ( $F$. oxysporum f. sp. lycopersici alone treatment), 900 to $1,500 \mathrm{CFU}$ (co-inoculation treatment), and 1,410 CFU in the distal roots (Fig. 4E and F).

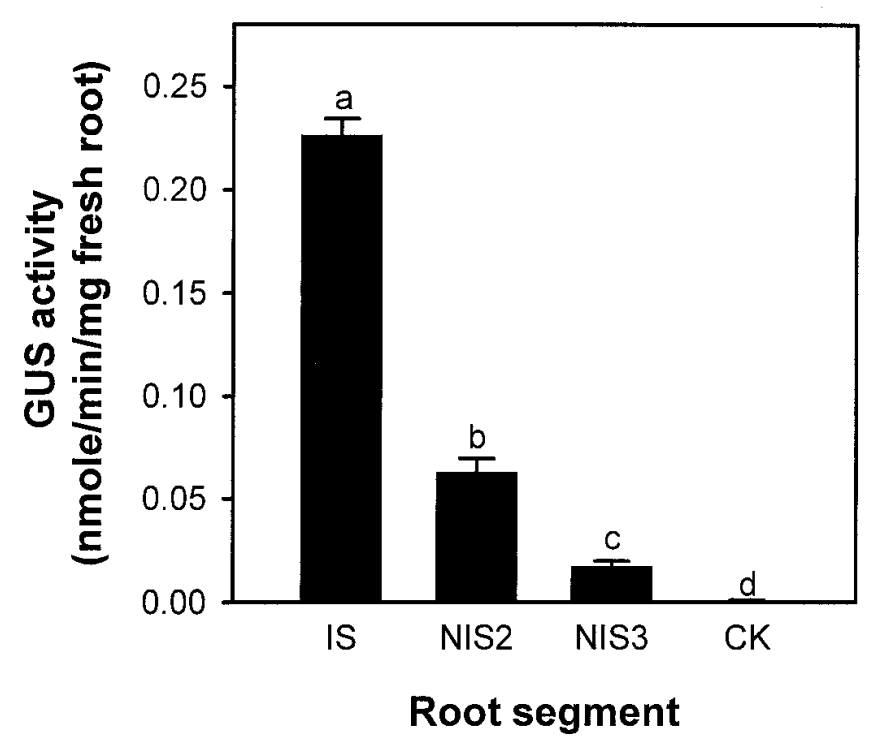

Fig. 2. $\beta$-glucuronidase (GUS) activity of different root segments sampled from tomato roots inoculated with a nonpathogenic Fusarium transformant 70T01. Inoculation site (IS) root segments, noninoculation site root segments $2 \mathrm{~cm}$ down from the IS (NIS2), segments from noninoculation sites $3 \mathrm{~cm}$ down from the IS (NIS3), and roots treated with water alone (CK). The bars $( \pm$ SE) followed by different letters are significantly different $(P<0.05$, Student-Newman-Keuls method, $n=5$ replicates with four to five roots per replicate).
In the second experiment, root segments within plugs that received strain 70T01 inoculum had significantly higher GUS activity than roots from outside the plug (exo-plug roots) for the entire duration of the experiment. GUS activity levels of both inplug roots and roots in the soil remained relatively stable for 30 days. The highest GUS activity levels were found in roots that were co-inoculated with both strain $70 \mathrm{~T} 01$ and $F$. oxysporum f. sp. lycopersici. At day 10, GUS activity levels in these roots were nearly double that found in roots treated with strain 70T01 alone. Co-inoculation, however, did not lead to any great increase in GUS activity levels for the roots outside of the plug. Background levels of GUS activity were found in $F$. oxysporum f. sp. lycopersici- or water-treated tissues at 20 days after transplantation, but the levels were significantly less than those seen in roots inoculated with either strain $70 \mathrm{~T} 01$ or $70 \mathrm{~T} 01$ plus $F$. oxysporum f. sp. lycopersici.

Fungal population sizes of CFU per milligram of root for strain 70T01 when applied alone declined in the in-plug roots from 150 to less than 25 over a period of 20 days and remained stable. In the roots outside the plugs, strain 70T01 was barely detectable even at 4 weeks posttransplanting. In addition, its population size at day 10 was significantly less in the presence of $F$. oxysporum $\mathrm{f}$. sp. lycopersici than that found in roots treated with strain 70T01 alone. The population size of $F$. oxysporum f. sp. lycopersici reached its maximum values in plug roots after 10 days and declined thereafter, both when strain $F$. oxysporum f. sp. lycopersici was added alone as well as when it was added in combination with strain 70T01. In exo-roots, CFU of $F$. oxysporum f. sp. lycopersici was more than 10-fold higher than in the plug roots (870 versus 50) at 10 days after transplantation. Population sizes declined to approximately 450 after a period of 20 days and remained stable. In the presence of strain 70T01, initial $F$. oxysporum f. sp. lycopersici population sizes in the exo-plug roots were about half of that when added alone, and here also CFU declined by half after 20 days.

\section{DISCUSSION}

The utilization of GUS expression in NP F. oxysporum strain $70 \mathrm{~T} 01$ provided an ideal histochemical marker to clearly differentiate and characterize the colonization of root tissues by pathogenic and NP F. oxysporum isolates under aseptic conditions. The

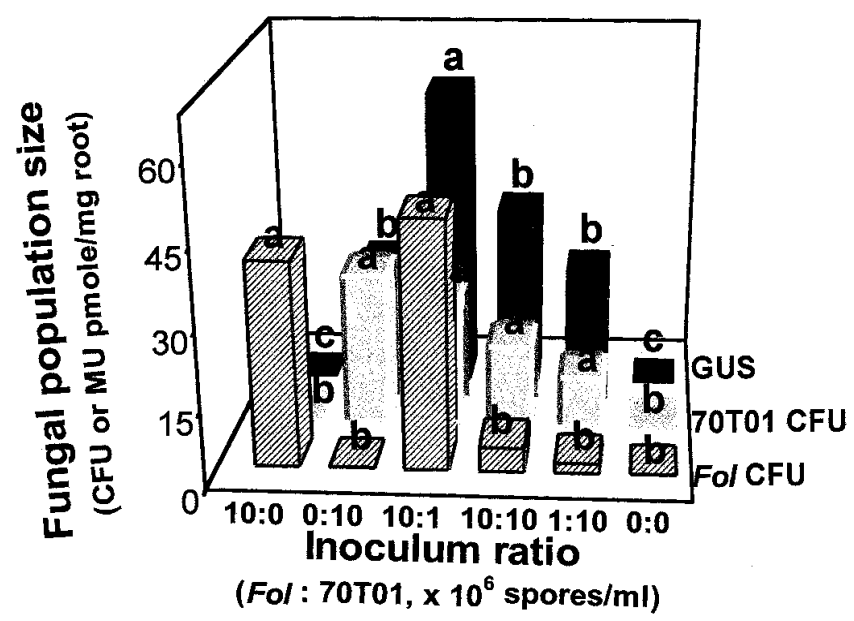

Fig. 3. The effect of varying inoculum ratios between a nonpathogenic Fusarium oxysporum transformant strain 70T01 and a pathogenic strain $F$. oxysporum f. sp. lycopersici on $\beta$-glucuronidase (GUS) activity and $F$. oxysporum $\mathrm{f}$. sp. lycopersici population size in tomato root. Roots were inoculated with different $F$. oxysporum $\mathrm{f}$. sp. lycopersici/70T01 spore density ratios: $10^{7}: 0,0: 10^{7}, 10^{7}: 10^{6}, 10^{7}: 10^{7}$, or $10^{6}: 10^{7}$ spores per ml. Means with different letters within CFU or GUS activity are significantly different $(P<0.05$, Student-Newman-Keuls method). 
fact that strain 70T01 had a different colonization location from the pathogen $F$. oxysporum f. sp. lycopersici in tomato roots (Fig. 1) suggests that any direct interactions that may arise between the pathogen and strain 70T01 likely occur at the root surface cell layers. Thus, extensive colonization by strain 70T01, prior to invasion by the pathogen, is likely of great importance in the direct interactions with the pathogen for the reduction of pathogen's infection and thus for disease reduction.

The mycelia of strain 70T01 were also localized in tomato roots under a hydroponic cultivation system (21) but their interactions with pathogen were not identified. The present study clearly demonstrated that the two organisms had their own colonization patterns and sites. Also, we did not find a reduction in staining quality after 10 days of inoculation as reported by other re- searchers (21). Although direct interaction sites between pathogenic and NP $F$. oxysporum were also speculated on by others $(24,29)$, our study provided substantial evidence for these suggestions. We found that $F$. oxysporum $\mathrm{f}$. sp. lycopersici mycelia were rarely observed at sites colonized by strain 70T01 in root sections from plants that were inoculated with both strain 70T01 and $F$. oxysporum f. sp. lycopersici. Similarly, strain 70T01 mycelia were rarely observed in segments where abundant $F$. oxysporum f. sp. lycopersici mycelia were found, suggesting that Fusarium spp. can exclude each other from the same ecological niche. This suggests competition for space and that disease reduction by the NP $F$. oxysporum strain could be caused by occupation of infection sites. This kind of competition pattern was also found in biocontrol systems using bacterial strains (10).

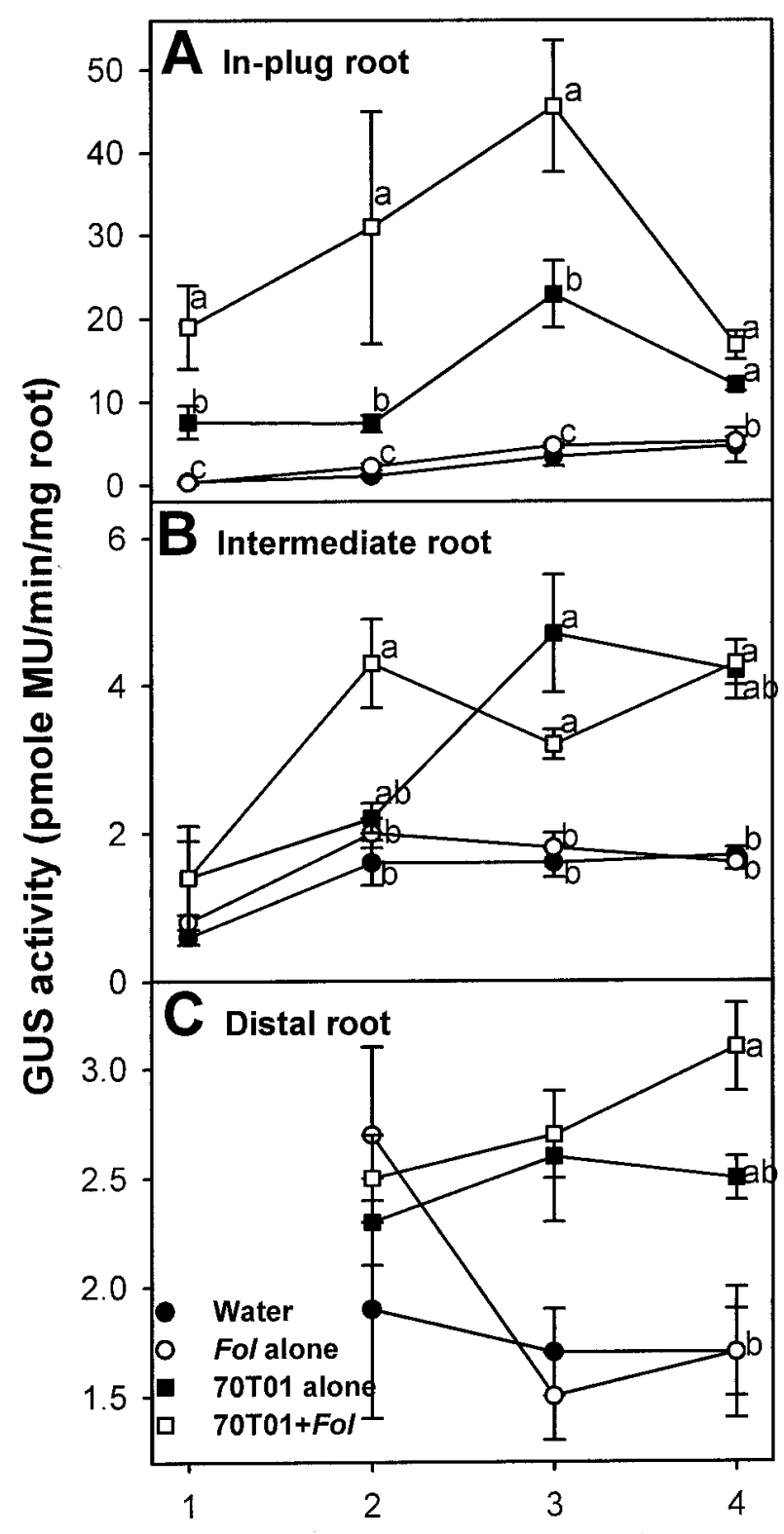

Time (weeks after transplant)

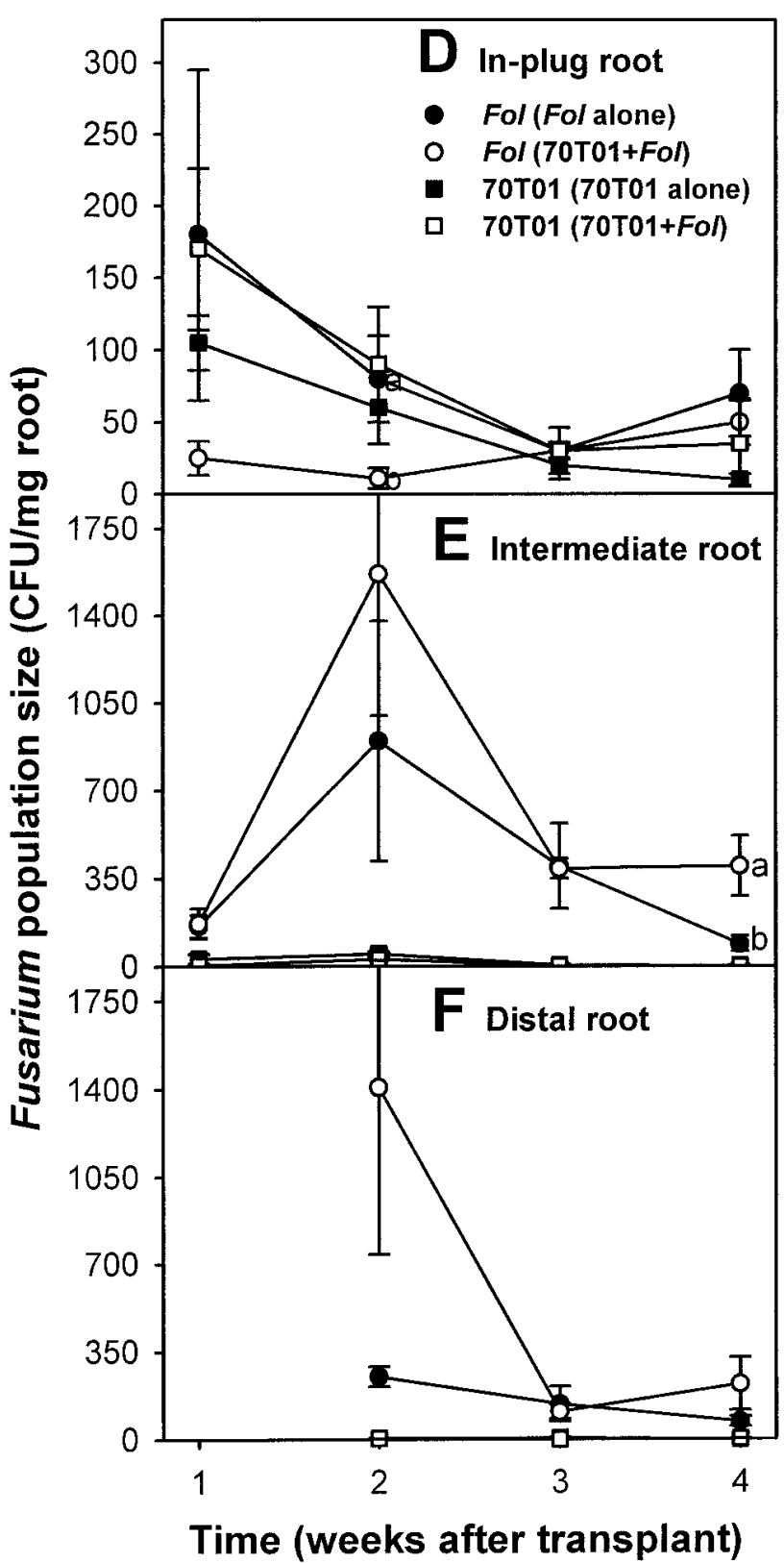

Fig. 4. A to $\mathbf{C}, \beta$-glucuronidase (GUS) activity and $\mathbf{D}$ to $\mathbf{F}$, population size (CFU) in different tomato root zones. In $\mathbf{D}$, the legends in parentheses are the treatment combinations. No CFU was detected for strain $70 \mathrm{~T} 01$ in roots treated with either water or Fusarium oxysporum f. sp. lycopersici alone and for strain F. oxysporum f. sp. lycopersici in roots treated with either water or $70 \mathrm{~T} 01$ alone. Tomato transplants were inoculated with a nonpathogenic Fusarium strain 70 T01 transformed with the GUS gene. Both GUS activity and CFU were determined after transplanting into either $F$. oxysporum f. sp. lycopersici-inoculated $(70 \mathrm{~T} 01+$ F. oxysporum f. sp. lycopersici) or non-F. oxysporum f. sp. lycopersici-inoculated soil (70T01). The in-plug root zone was sampled from the root segments inside the transplant (Promix) plug while the exo-plug root zones (intermediate and distal) were sampled from the roots outside the plug. Results presented are from one experiment. The means and standard error were obtained from four replicates. Only values followed by different letters within the same time are significantly different from each other $(P<0.05)$. 
These observations were consistent with GUS activity and CFU density results when different $F$. oxysporum f. sp. lycopersicil 70T01 inoculum density ratios were used. Roots inoculated with strain 70T01 at populations equal to or higher than that of strain $F$. oxysporum f. sp. lycopersici had similar GUS activity levels as those inoculated with strain $70 \mathrm{T01}$ alone. In contrast, F. oxysporum f. sp. lycopersici population sizes in the same roots had significantly lower CFU when inoculated at a lower number than strain 70T01, suggesting infection site competition by strain 70T01 with higher densities effectively excluding the pathogen $F$. oxysporum f. sp. lycopersici from colonizing the roots. These inoculum density relationships also explain why for many NP Fusarium strains effective disease reduction only occurs when the antagonist population size is substantially greater than that of the pathogen $(1,24)$, although there are exceptions for some strains (16). At the same time, when strain 70T01 mycelia were found colonizing the inner cortex cell layers, they were invariably associated with $F$. oxysporum $\mathrm{f}$. sp. lycopersici infection as observed in the root sections. This indicates that the pathogen can predispose host tissues for strain 70T01 to reach the inner root cells accessible, and could be the reason that co-inoculation of strain F. oxysporum f. sp. lycopersici and 70T01 at the same density ratio had higher GUS activity.

Host defense reactions in 70T01-inoculated roots were commonly expressed as increased cell wall thickness or deposition of papilla structures on the cell wall. Cell enlargement or cell deformation, reported by Olivain and Alabouvette (21), or other reactions associated with host defense at sites of pathogen invasion $(2,4-6,23,26)$ were not commonly observed in tissues colonized by strain 70 T01 alone. Papillae-like structures could be seen in sites where strain 70T01 mycelia attempted to penetrate root cells on slides under the microscope. Papillae often contain phenolic deposits and are commonly associated with sites of unsuccessful penetration of cell walls by incompatible pathogens $(21,23,31)$. Thus, locally induced defense reactions activated by strain 70T01 colonization may also play a role in preventing the invasion by $F$. oxysporum f. sp. lycopersici. These defense reactions had limited impact systematically because the pathogen population sizes in exo-plug root zones were not greatly reduced by the inoculation of strain 70T01.

Of the different root segments, the exo-roots had much larger $F$. oxysporum f. sp. lycopersici population sizes than the in-plug roots, suggesting that $F$. oxysporum f. sp. lycopersici aggressively colonizes young root tissues and, once inside the plant, spreads unimpeded upward through the vascular bundles. As indicated by all measurements (root staining, GUS activity, and CFU measurement in the outside-plug [intermediate and distal]) root segments, strain 70T01 does not spread far beyond the inoculation site. Plants inoculated with strain 70T01 and transplanted into soil with a high population of pathogenic isolates, thus, would not be expected to be protected at the newly growing root zones.

Measurements of 70T01 population sizes using GUS activity levels were not related to CFU in the same roots. GUS activity was greatest in roots treated with strain $F$. oxysporum $\mathrm{f}$. sp. lycopersici plus 70T01 at a 1:1 ratio, but the CFU of the antagonist was not significantly different from those of other 70T01treated roots. In the experiments with transplants in soil, GUS activity by strain 70T01 in the in-plug roots remained constant or increased slightly over the 4-week experiments, whereas, population sizes of strain 70T01 based on CFU decreased rapidly over the time. Roots from plants growing in soil infested with strain $F$. oxysporum f. sp. lycopersici had higher GUS activities than those treated with strain 70T01 alone. In contrast, both strain 70T01 and F. oxysporum f. sp. lycopersici population sizes in co-inoculated roots were generally comparable to or lower than those in roots inoculated with a single strain. These results indicated that root colonization by the pathogen was greatly affected by the ratio of the pathogen population size to that of strain 70T01.
In a previous study, we demonstrated that the CFU method was less sensitive to the mycelia and more prone to variability caused by the presence of spores or efficacy of the tissue maceration (3). GUS activity reflected more realistically the quantity of mycelia in the in-plug root segments during the time course. The quantity of mycelia appear to remain fairly stable or increase significantly in the plug roots in the first 3 weeks. This suggests that the onset of disease caused by the pathogen may allow spread of strain 70T01, thus producing greater GUS activity. This supposition is supported by the data, showing that a $1: 1$ ratio of strain $F$. oxysporum f. sp. lycopersici/70T01 produced the highest GUS activity and a high $F$. oxysporum f. sp. lycopersici population size. Estimations of strain 70T01 population size in exo-plug root zones, where the sizes were very low, provided similar trends for both GUS activity levels and CFU.

Inoculation of other strains of NP F. oxysporum in a root system could have a different impact on the pathogenic colonization. For example, roots inoculated with NP $F$. oxysporum strains selected by Larkin and Fravel (16) and Larkin et al. $(17,18)$ did not reduce colonization by the Fusarium pathogen. Other reports demonstrated that presence of NP F. oxysporum strain resulted in lower colonization by pathogenic strain, and the effect was reciprocal $(9,28)$. Mycelial development in the vicinity of tomato roots also indicated that various Fusarium strains had their own developmental pattern (29). Thus, different NP F. oxysporum strains could have different action models and different effects on pathogens. The results presented here indicate that the fungal population levels of either pathogen or NP F. oxysporum strain depend on the root zones, inoculation density ratios, and time. These factors may account for some contradictory results reported for the colonization levels of either pathogen or NP when the two organisms were co-introduced into a host root system and, thus, strongly suggest that the technique used to measure fungal population sizes in a plant tissue may be a very important factor affecting experimental outcomes.

\section{ACKNOWLEDGMENTS}

This project was funded in part by Environment Canada and the Agriculture and Agri-Food Canada Matching Investment Initiative program. We thank K. Dobinson for advice, J. Velema for technical assistance, and D. Fravel for helpful comments on the draft of the manuscript.

\section{LITERATURE CITED}

1. Alabouvette, C., and Couteaudier, Y. 1992. Biocontrol of fusarium wilts with nonpathogenic fusaria. Pages 415-426 in: Biological Control of Plant Diseases. E. C. Tjamos, G. C. Papavizas, and R. J. Cook, eds. Plenum Press, New York.

2. Baayen, R. P., Ouellette, G. B., and Rioux, D. 1996. Compartmentalization of decay in carnations resistant to Fusarium oxysporum f. sp. dianthi. Phytopathology 86:1018-1031.

3. Bao, J. R., Velema, J., Dobinson, K. F., and Lazarovits, G. 2000. Using GUS expression in a nonpathogenic Fusarium oxysporum strain in measuring fungal biomass. Can. J. Plant Pathol. 22:70-78.

4. Biles, C. L., and Martyn, R. D. 1989. Local and systemic resistance induced in watermelons by formae speciales of Fusarium oxysporum. Phytopathology 79:856-860.

5. Bishop, C. D., and Cooper, R. M. 1983. An ultrastructural study of root invasion in three vascular wilt diseases. Physiol. Plant Pathol. 22:15-27.

6. Brammall, R. A., and Higgins, V. J. 1988. A histochemical comparison of fungal colonization in tomato seedlings susceptible or resistant to Fusarium crown and root rot disease. Can. J. Bot. 66:915-925.

7. Couteaudier, Y., Daboussi, M. J., Eparvier, A., Langin, T., and Orcival, J. 1993. The GUS gene fusion system (Escherichia coli $\beta$-D-glucuronidase gene), a useful tool in studies of root colonization by Fusarium oxysporum. Appl. Environ. Microbiol. 59:1767-1773.

8. Dhingra, O. D., and Sinclair, J. B. 1995. Basic Plant Pathology Methods. Lewis Publishers, Boca Raton, FL.

9. Eparvier, A., and Alabouvette, C. 1994. Use of ELISA and GUStransformed strains to study competition between pathogenic and nonpathogenic Fusarium oxysporum for root colonization. Biocontrol Sci. 
Technol. 4:35-47.

10. Etchebar, C., Trigaletdemery, D., Vangijsegem, F., Vasse, J., and Trigalet, A. 1998. Xylem colonization by an $\mathrm{HrcV}(-)$ mutant of Ralstonia solanacearum is a key factor for the efficient biological control of tomato bacterial wilt. Mol. Plant-Microbe Interact. 11:869-877.

11. Gallagher, S. R. 1992. Quantitation of GUS activity by fluorometry. Pages 47-59 in: GUS Protocols: Using the GUS Gene as a Reporter of Gene Expression. S. R. Gallagher, ed. Academic Press, New York.

12. Green, H., and Jensen, D. F. 1995. A tool for monitoring Trichoderma harzianum: II. The use of a GUS transformant for ecological studies in the rhizosphere. Phytopathology 85:1436-1440.

13. Handelsman, J., and Stabb, E. V. 1996. Biocontrol of soilborne plant pathogens. Plant Cell 8:1855-1869.

14. Jefferson, R. A. 1987. Assaying chimeric genes in plants: The GUS gene fusion system. Plant Mol. Biol. Rep. 5:387-405.

15. Komada, H. 1975. Development of a selective medium for quantitative isolation of Fusarium oxysporum from natural soil. Rev. Plant Prot. Res. 8:115-125.

16. Larkin, R. P., and Fravel, D. R. 1999. Mechanisms of action and dose-response relationships governing biological control of Fusarium wilt of tomato by nonpathogenic Fusarium spp. Phytopathology 89: 1152-1161.

17. Larkin, R. P., Hopkins, D. L., and Martin, F. N. 1993. Effect of successive watermelon plantings on Fusarium oxysporum and other microorganisms in soils suppressive and conducive to Fusarium wilt of watermelon. Phytopathology 83:1097-1105.

18. Larkin, R. P., Hopkins, D. L., and Martin, F. N. 1996. Suppression of Fusarium wilt of watermelon by nonpathogenic Fusarium oxysporum and other microorganisms recovered from a disease-suppressive soil. Phytopathology 86:812-819.

19. Liljeroth, E., Jansson, H. B., and Schafer, W. 1993. Transformation of Bipolaris sorokiniana with the GUS gene and use for studying fungal colonization of barley roots. Phytopathology 83:1484-1489.

20. Monke, E., and Schafer, W. 1993. Transient and stable gene expression in the fungal maize pathogen Cochliobolus heterostrophus after transformation with the $\beta$-glucuronidase (GUS) gene. Mol. Gen. Genet. 241:73-80

21. Olivain, C., and Alabouvette, C. 1997. Colonization of tomato root by a nonpathogenic strain of Fusarium oxysporum. New Phytol. 137: 481-494.

22. Pierik, R. L. M. 1987. In Vitro Culture of Higher Plants. MartinusNijhoff Publishing, Dordrecht, Netherlands.

23. Pijut, P. M., Lineberger, R. D., Domir, S. C., Ichida, J. M., and Krause, C. R. 1990. Ultrastructure of cells of Ulmus americana cultured in vitro and exposed to the culture filtrate of Ceratocystis ulmi. Phytopathology 80:764-767.

24. Postma, J., and Luttikholt, A. J. G. 1996. Colonization of carnation stems by a nonpathogenic isolate of Fusarium oxysporum and its effect on Fusarium oxysporum f. sp. dianthi. Can. J. Bot. 74:1841-1851.

25. Punt, P. J., and van den Hondel, C. A. M. J. J. 1992. Transformation of filamentous fungi based on hygromycin $\mathrm{B}$ and phleomycin resistance markers. Methods Enzymol. 216:447-457.

26. Rey, P., Benhamou, N., and Tirilly, Y. 1998. Ultrastructural and cytochemical investigation of asymptomatic infection by Pythium spp. Phytopathology 88:234-244.

27. Roberts, C. A., Oliver, R. P., Punt, P. J., and van den Hondel, C. A. M. J. J. 1989. Expression of the Escherichia coli $\beta$-glucuronidase gene in industrial and phytopathologenic filamentous fungi. Curr. Genet. 15: 177-180.

28. Schneider, R. W. 1984. Effects of nonpathogenic strains of Fusarium oxysporum on celery root infection by $F$. oxysporum $\mathrm{f}$. sp. appi and a novel use of the Line weaver-Burke double reciprocal plot technique. Phytopathology 74:646-653.

29. Steinberg, C., Whipps, J. M., Wood, D., Fenlon, J., and Alabouvette, C. 1999. Mycelial development of Fusarium oxysporum in the vicinity of tomato roots. Mycol. Res. 103:769-778.

30. Stomp, A.-M. 1992. Histochemical localization of $\beta$-glucuronidase Pages 103-113 in: GUS Protocols: Using the GUS Gene as a Reporter of Gene Expression. S. R. Gallagher, ed. Academic Press, New York.

31. Tessier, B. J., Mueller, W. C., and Morgham, A. T. 1990. Histopathology and ultrastructure of vascular responses in peas resistant or susceptible to Fusarium oxysporum $\mathrm{f}$. sp. pisi. Phytopathology 80:756-764.

32. Thrane, C., Lübeck, M., Green, H., Degefu, Y., Allerup, S., Thrane, U., and Jensen, D. F. 1995. A tool for monitoring Trichoderma harzianum: I. Transformation with the GUS gene by protoplast technology. Phytopathology 85:1428-1435. 